\title{
La soberanía de los estados en épocas de globalización
}

\section{The sovereignty of the states in times of globalization}

\author{
Iur. Utr. Matthias Herdegen
}

\begin{abstract}
iur. utr. (Heidelberg); Director del Instituto de Derecho Internacional y del Instituto de Derecho Público de la Universidad de Bonn, Alemania; Profesor honorario Pontificia Universidad Javeriana; Profesor honorario Colegio Mayor de Nuestra Señora del Rosario; Miembro Correspondiente de la Academia Colombiana de Jurisprudencia; Miembro de la Comisión de Derechos Humanos de la Asociación de Derecho Internacional (International Law Association); Profesor visitante New York University (Global Law School); Profesor visitante Universidad de París I (Sorbona); Profesor asociado City University of Hong Kong; Profesor invitado Universidad Autónoma de México; entre otros.
\end{abstract}

Cómo citar: Herdegen, M. (2015). La soberanía de los estados en épocas de globalización. Inciso n¹7: $192-196$

\section{Soberanía como tema central del orden internacional}

Hace tres décadas, la soberanía estaba concebida como una roca sólida e inmóvil en un mundo dividido, como la suma de los poderes inherentes al Estado. Si se hubiera pronosticado lo que estamos observando hoy, hubiese pensado que hablamos de otro planeta. Es difícil imaginar:

- Que un día una fuerza multinacional con mandato del Consejo de Seguridad de la ONU derroca a un régimen militar en Haití, para reestablecer un gobierno democrático.

- Que la Corte Interamericana de Derechos Humanos declarará invalida una ley de amnistía para los escuadrones de la muerte en Perú.

- Que una corte internacional penal emitiría un mandato de captura contra el presidente de Sudán y el coronel Gadafi de Libia.

- Que la Unión Europea tendría que permitir el ingreso de productos genéticamente modificados en los EEUU, a la luz de una decisión de un organismo llamado Organización Mundial de Comercio (OMC).- - Que frente a un consejo de seguridad pasivo, la Asamblea General de la ONU haría un llamado a no reconocer la incorporación de Crimea a la Federación Rusa.

- Que un juez colombiano ordenará la restitución de un alcalde de Bogotá para cumplir con una medida cautelar de la Comisión Interamericana de Derechos Humanos.

- Que Grecia se convertiría en un protectorado de la UE y del Fondo Monetario Internacional, para salvar la estabilidad de una nueva moneda que se llamará Euro.

La soberanía es el concepto clave del orden internacional. Como un termómetro, como un sismógrafo refleja el desarrollo de la situación actual de la comunidad internacional y la relación entre los Estados como sus integrantes.

La soberanía reside en un conjunto de derechos y libertades al que pertenecen el respeto de la integridad territorial, la jurisdicción como potestad normativa en relación con el territorio y la población, y la igualdad soberana de los estados en el sentido expresado en la Carta de las Naciones Unidas (art. $2^{\circ}$, núm. 1 y 4 ). En el derecho internacional clásico, la soberanía tenía mucho que ver con la dominación fáctica, es decir, 
más con el poder estatal existente, y menos, con un orden material de valores. Hasta la Primera Guerra Mundial, esta implicaba un derecho a la guerra, un jus ad bellum. Soberanía así significaba la ley del más fuerte.

En 1986, la Corte Internacional de Justica declaraba en el "Caso Nicaragua", la libertad de escogencia de un sistema político como atributo de la soberanía estatal. En las últimas décadas se han producido al respecto cambios bastante dramáticos hacia otra visión de la soberanía.

La interpretación de la soberanía estatal oscila entre dos polos. El primero, resalta al aspecto defensivo de esta como protección a la autodeterminación y como defensa frente a intromisiones externas. El segundo, destaca el vínculo de la soberanía con los valores fundamentales del derecho internacional que permean el mundo de los Estados como comunidad de derecho.

Esta posición une la soberanía con el desarrollo dinámico del orden internacional y sugiere una especie de condicionalidad de la soberanía a la luz de un orden internacional de valores. Aquellos que integran la comunidad internacional, los cuales son:

- La integridad territorial,

- La no-intervención en los asuntos internos,

- La autodeterminación de los pueblos $\mathrm{y}$

- Los derechos humanos que se radican en la dignidad humana.

Son justamente estos valores los que hoy en día condicionan la soberanía de los Estados.

La soberanía de Rusia la autoriza a defender su integridad frente a rebeldes que buscan la secesión de regiones en Caucasia, pero no le permite anexar territorios ajenos o intervenir en países vecinos. $\mathrm{La}$ soberanía tampoco admite perseguir y discriminar minorías, fomentar o albergar grupos de terrorismo internacional.

\section{El impacto de la globalización}

La globalización es, inicialmente, un fenómeno económico. La integración de mercados de productos y mercancías, de capital y de servicios aumenta la interdependencia de los países. Se basa en un régimen económico internacional con reglas sobre el libre comercio y la protección de la inversión extranjera. La globalización se extiende a las redes de comunicación, a las redes de energía y de transporte. El manejo del ciberespacio no se deja captar con viejos conceptos de la soberanía, aunque algunos pocos países intentan construir muros alrededor de la comunicación electrónica. Con los productos y las comunicaciones viajan otros agentes. Las culturas se vuelven peregrinas del mundo. Pero también las armas, amenazas terroristas y el espionaje de datos atraviesan el globo.

\section{Empatía y moral universal}

La globalización tiene otra faceta muy importante: Fomenta la empatía a través de los continentes. El genocidio de hace un siglo en Armenia, apenas está presente en la memoria colectiva de nuestros pueblos, pero el holocausto del Tercer Reich y las atrocidades más recientes en África central y en otras latitudes sí que lo están.

La jurisprudencia penal internacional es un instrumento importante para consolidar esta conciencia. Somos testigos del nacimiento de una conciencia colectiva a nivel internacional, de una especie de moral universal.

\section{Soberanía y autodeterminación democrática}

La soberanía presta el marco en el que se puede desplegar el derecho de autodeterminación de los pueblos y con ello, la formación de la voluntad democrática por parte de los ciudadanos. La soberanía como concepto necesario para fundamentar un orden democrático, adquiere así su sentido moderno. Este es el aspecto más encantador y simpático de ella.

La consecuencia del derecho de autodeterminación es el principio del consentimiento expreso del Estado para cada tratado internacional. En la libre sumisión a obligaciones contractuales se manifiesta la 
soberanía. En nuestras democracias la aprobación del parlamento o del pueblo mediante referendo otorga a los acuerdos internacionales legitimidad democrática.

Los Estados y pueblos de la Unión Europea han ejercido su derecho de autodeterminación en el sentido de una amplia restricción de su soberanía, en favor de una integración europea: Algunos hablan, con referencia a los Estados miembros de la Unión Europea, de un "torso de soberanía". Una reciente y sumamente importante transferencia de poderes se refiere a la soberanía monetaria, cuyo ejercicio tiene tanta repercusión sobre toda la vida económica en la zona del euro. Algunos Estados miembros de la Unión Europea como el Reino Unido optaron por preservar esta faceta de su soberanía.

Cada Estado puede formular requisitos especiales en su Constitución que condicionen la aprobación de tratados. Nuestras cortes constitucionales, tanto en Alemania como en Colombia, controlan con estricta vigilancia la concordancia de tratados con el orden constitucional. En Alemania el gran tema es la transferencia de competencias a la Unión Europea y su ejercicio intra o ultra vires, particularmente con referencia a la política del Banco Central Europeo de apoyar a los países de la zona Euro con altas deudas; en Colombia los temas son los acuerdos de libre comercio, procesos de paz, o el Estatuto de Roma. Este último, ratificado por el presidente Andrés Pastrana quien formuló algunas declaraciones que aumentan la libertad de acción de Colombia en contexto con una paz negociada. Era un mecanismo para establecer la concordancia entre posibles opciones políticas con las obligaciones internacionales de Colombia.

La soberanía nacional es la base conceptual del llamado "dualismo" con respecto a la relación entre el derecho internacional y el nacional.

El dualismo es la perspectiva que prevalece en el mundo de hoy. El derecho internacional determina las obligaciones y su ámbito a nivel internacional, mientras el derecho interno determina el cumplimento al interior del Estado y los efectos del derecho internacional tanto para los órganos del estado como para particulares. Hoy, nuestras cortes buscan una armonización de ambos órdenes jurídicos en el mayor grado posible, para evitar conflictos y responsabilidad internacional. En algunos casos especiales surgen tendencias "monistas" en pro del derecho internacional. Un ejemplo es la jurisprudencia de la Corte Interamericana de Derechos Humanos que declaró ciertas leyes $u$ otros actos internos sin vigencia, porque violaron obligaciones elementales del Estado bajo la Convención Americana de Derechos Humanos.

\section{Soberanía y vinculación de los Estados a un orden material de valores: derechos humanos}

La protección moderna de los derechos humanos remueve la vieja idea de soberanía como un dominio interno ilimitado. Especialmente, la inclusión de la protección de los derechos humanos en el concepto de "paz mundial" (en los términos del Artículo 39 de la Carta de las Naciones Unidas) conduce también a una persistente limitación de la soberanía estatal y de la igualdad soberana. De esta manera, el potencial de acción del Consejo de Seguridad permite, conforme al capítulo vir de la Carta de las Naciones Unidas, dramáticas intromisiones en la soberanía estatal encaminadas a proteger los derechos humanos: Haití, Somalia, la ex Yugoslavia.

En el World Summit de septiembre del 2005, se ha abierto paso la idea de cierta responsabilidad de protección e impedimento de graves violaciones a los derechos humanos ("responsability to protect") por parte de la comunidad internacional. Esta responsabilidad de protección se dirige a tomar medidas a través del Consejo de Seguridad de las Naciones Unidas para evitar el genocidio, los crímenes de guerra, la limpieza étnica y los crímenes contra la humanidad.

Tal y como lo dejó claro el Papa Benedicto XVI en su discurso ante la Asamblea General de las Naciones Unidas en el año 2008, la protección de los derechos humanos como principio del orden internacional precede a la soberanía estatal y establece sus límites inmanentes:

\footnotetext{
"El reconocimiento de la unidad de la familia humana y la atención a la dignidad innata de cada hombre y mujer adquiere hoy un nuevo énfasis con el principio de la responsabilidad de proteger. ... Todo Estado tiene el deber primario de proteger a la propia población de violaciones graves y continuas de los derechos humanos, como también de las consecuencias
} 
de las crisis humanitarias, ya sean provocadas por la naturaleza o por el hombre. Si los Estados no son capaces de garantizar esta protección, la comunidad internacional ha de intervenir con los medios jurídicos previstos por la Carta de las Naciones Unidas y por otros instrumentos internacionales. La acción de la comunidad internacional y de sus instituciones, dando por sentado el respeto de los principios que están a la base del orden internacional, no tiene por qué ser interpretada nunca como una imposición injustificada y una limitación de soberanía". (Benedicto XVI; 2008)

A través de varios mecanismos, nuestros países han incorporado los derechos humanos en nuestro ordenamiento constitucional. En particular, los fundamentales se aplican a la luz de estándares internacionales, como resultado de la Convención Americana de Derechos Humanos o su contraparte europea.

\section{Defensa de la seguridad internacional}

La protección de la seguridad internacional de conformidad con el capítulo viI de la Carta de las Naciones Unidas también rompe con tradicionales concepciones de soberanía. Hoy el Estado agresivo tiene que soportar limitaciones en su estatus soberano.

El sistema de seguridad colectiva de las Naciones Unidas, interviene en el ámbito interno de los Estados a través de resoluciones dirigidas a los grupos enfrentados en guerras civiles, y a otros grupos armados o terroristas. El procedimiento del Consejo de Seguridad contra Corea del Norte y contra Irán muestra hoy que el desarrollo de armas nucleares no puede -sin más- formar parte de las opciones permitidas en el ejercicio de la soberanía estatal.

Pocas son las limitaciones unánimemente reconocidas que tiene el Consejo de Seguridad en su actividad de intervención sobre la soberanía estatal. A muchos les podrá parecer que el Consejo de Seguridad, es el verdadero soberano del mundo de los Estados. Esta interpretación exagera la actual situación.

\section{EI derecho económico internacional}

Un condicionamiento de la soberanía resulta del derecho económico internacional. Las reglas de la Organización Mundial de Comercio no le permiten a China un control ilimitado de la importación de libros y otros productos audiovisuales para proteger lo que China llama la moral "'publica". Tampoco puede reservar a su propia industria, el acceso a sus recursos naturales como tierras raras, sino tiene que actuar de forma no discriminatoria frente a empresas extranjeras. La Unión Europea permite la importación de carne con residuos mínimos de hormonas. Tratados sobre la inversión obligan a los Estados contratantes a tratar al inversionista de manera justa y equitativa, lo que implica el pago de compensación cuando realiza cambios radicales en la legislación que afectan la inversión y su valor económico.

\section{La mirada hacia el interior de los Estados}

Los derechos humanos influyen en las estructuras internas. Observamos también una nueva insistencia en el marco regional, en principios democráticos y en el respeto de la formas de una constitución democrática. La toma de resoluciones por parte del Consejo de Seguridad de las Naciones Unidas sobre actores no estatales, así como la responsabilidad individual conforme al derecho penal internacional, pasan por encima de arraigadas concepciones de soberanía.

Se presenta una conexión de la soberanía con el concepto de gobierno responsable y transparente (Good Governance) y los principios del Estado de derecho. Lucha para la transparencia, nulidad de contratos o de concesiones que se obtuvieron mediante corrupción.

\section{Fortalecimiento del Estado moderno a través de la cooperación limitante de la soberanía}

Los vínculos del derecho internacional no pueden entenderse simplemente como erosión de la soberanía estatal. El orden internacional asegura al Estado una superioridad frente a compañías transnacionales, y organizaciones no estatales. De esta manera, es justamente el Estado, inserto en su red internacional, el que se erigió como piedra angular o "rocher de bronze" en el marco de la actual crisis financiera.

En el ámbito global debe profundizarse la cooperación formal. La participación más amplia de los países en vía de desarrollo y de potencias emergentes por intermedio del G-20, fortalece las bases de efectividad, legitimidad y de aceptación de un "manejo global". 


\section{Un nuevo balance entre soberanía y los intereses de la comunidad internacional}

El vínculo de los valores fundamentales con el orden de derecho internacional dota al concepto de soberanía de la necesaria elasticidad y flexibilidad. El condicionamiento de la soberanía estatal a través de valores fundamentales del derecho internacional protege la soberanía estatal de su descrédito, como abrigo de los actos de injusticia organizados por el Estado y como amenaza contra otros Estados. Por lo demás, la sujeción a jurisdicciones internacionales es un signo de soberanía estatal en este doble sentido.

La soberanía atada a valores conduce a una nueva interpretación, que a su vez permite proteger tanto a los ciudadanos, como a los intereses de la comunidad de los Estados. De esta manera, se plantea la idea directriz de una soberanía abierta hacia la comunidad internacional, marcada por el respeto de los derechos humanos. Este significado moderno de soberanía es, por excelencia, la fuente de legitimidad del Estado soberano en el mundo de hoy.

Por otro lado, importa respetar una textura imprescindible de la soberanía en pro de la autonomía de los Estados en el contexto de escogencias políticas, económicas y sociales. Desde esta perspectiva la soberanía protege la diversidad y el pluralismo de culturas jurídicas y políticas.

Buscar el justo equilibrio entre los valores universales por un lado, y el debido respeto hacia esta diversidad y autonomía, es un gran desafío para el orden internacional. También es una tarea muy noble para la formación académica. 